\title{
Analisis Penerapan Perencanaan Pajak Penghasilan PPh Badan dan Fi- nal Sebagai Upaya Mengefisienkan Beban Pajak Pada Perusahaan PT Lippo Karawaci Tbk Tahun 2017 - 2019
}

\author{
Muhammad Helmi Raditya ${ }^{1}$, Zulpahmi ${ }^{2}$, Sumardi ${ }^{3}$ \\ Program Studi Akuntansi, Universitas Muhammadiyah Prof. DR. HAMKA, Jakarta, Indonesia
}

\author{
Corresponding Author \\ Nama Penulis : Muhammad Helmi Raditiya \\ E-mail :e-mail: muhammad.helmi49@yahoo.com
}

\begin{abstract}
Abstrak
Penelitian ini bertujuan untuk mengetahui perencanaan pajak yang dilakukan oleh PT. Lippo Karawaci Tbk dengan menggunakan PPh Badan dan PPh Final untuk perhitungan beban pajak dan mengetahui perbandingan perhitungan pajak dengan menggunakan PPh Badan dan PPh Final dalam mengefisienkan beban pajak pada tahun 2017-2019. Penelitian ini menggunakan metode deskriptif, analisis yang digunakan adalah dengan mengumpulkan data perusahaan yang digunakan dalam melakukan tax planning serta melihat sumber-sumber penghasilan serta mendefinisikan jenis biayabiaya dan melakukan tax planning. Adapun teknik pengolahan data yang digunakan adalah analisis deskriptif. Hasil dari penelitian ini terlihat pada tahun 2019 PPh Badan sebesar Rp 335.197.000 sedangkan PPh Final sebesar Rp 276.148.335, untuk tahun 2018 PPh Badan sebesar Rp 403.247.684 sedangkan PPh Final sebesar Rp 276.424.450, dan untuk tahun 2017 PPh Badan sebesar Rp 228.489.600 sedangkan PPh Final sebesar Rp 276.602.975.
\end{abstract}

Kata kunci : Penerapan Perencanaan Pajak, Beban Pajak

\begin{abstract}
This study aims to determine the tax planning carried out by PT. Lippo Karawaci Tbk by using Corporate Income Tax and Final Income Tax for the calculation of tax expense and for knowing the comparison of tax calculations using Corporate Income Tax and Final Income Tax in order to streamline the tax expense in 2017-2019. This research uses descriptive method, the analysis used to collect company data used in doing tax planning and looking at the sources of income and defining the types of costs and carrying out tax planning. The data processing technique used is descriptive analysis. The results of this study can be seen that in 2019 the Corporate Income Tax is IDR 335,197,000 while the Final Income Tax is IDR 276,148,335, for 2018 the Corporate Income Tax is IDR $403,247,684$ while the Final Income Tax is IDR 276,424,450, and for 2017 the Corporate Income Tax is IDR IDR 228,489,600 while the Final Income Tax is IDR 276,602,975.
\end{abstract}

Keywords : Application of Tax Planning, Tax Expense 


\section{PENDAHULUAN}

Mengefisienkan beban pajak adalah salah satu cara yang dilakukan oleh sebuah perusahaan melalui manajemennya, berusaha agar dapat melakukan penghematan atau pengurangan pajak. Perencanaan pajak adalah suatu proses usaha-usaha wajib pajak atau sekelompok wajib pajak untuk mengefisiensikan beban pajak atau kewajiban pajaknya, baik yang berupa penghasilan maupun pajakpajak yang lain melalui pemanfaatan celah-celah dalam perundang-undangan perpajakan.

Dengan dilakukannya perencanaan pajak yang baik dan tepat, maka perusahaan dapat mengoptimalkan pajak yang harus dibayar sehingga dapat digunakan untuk membiayai pengeluaran yang lainnya. Berdasarkan latar belakang pendahuluan, maka penulis tertarik untuk dilakukannya penelitian mengenai “Analisis Penerapan Perencanaan Pajak Penghasilan PPh Badan dan Final Sebagai Upaya Mengefisienkan Beban Pajak pada Perusahaan PT. Lippo Karawaci Tbk Tahun 2017-2019”.

\section{TINJAUAN PUSTAKA}

\section{Pengertian Perencanaan Pajak}

Menurut beberapa ahli mengenai pengertian perencanaan pajak, dapat disimpulkan bahwa definisi perencanaan pajak merupakan strategi di bidang perpajakan yang dilakukan oleh pribadi maupun badan usaha, dalam rangka penghematan agar pajak yang dibayarkan oleh perusahaan benar-benar efisien. Adapun tujuan dari perencanaan pajak adalah sebagai berikut:

1. Meminimalisir beban pajak yang terutang

2. Memaksimalkan laba setelah pajak

3. Meminimalisir terjadinya kejutan pajak (tax surprise) jika terjadi pemeriksaan pajak

4. Memenuhi kewajiban perpajakan secara efisien dan efektif

\section{PPh Final (Pasal 4 ayat 2)}

\section{Pengertian PPh Final (Pasal 4 ayat 2)}

Wirawan B. Ilyas dan Rudi Suhartono (2013 : 163), mendefinisikan bahwa :

"PPh Final (Pasal 4 ayat 2) adalah peraturan pelaksanaannya menyebutkan PPh yang terutang atas penghasilan tertentu ialah tarif dikalikan dengan jumlah penghasilan bruto dan bersifat final, tarif tersebut sudah memperhitungkan biaya usaha yang terkait penghasilan final tersebut sehingga biaya usaha yang terkait penghasilan final tidak diperkenankan sebagai biaya fiskal/pengurangan penghasilan non final". Berdasarkan definisi di atas PPh Final adalah pemajakan atas penghasilan tertentu dihitung atas dasar tarif yang ditetapkan dikalikan dengan penghasilan bruto dan bersifat final.

\section{Mengefisiensikan Beban Pajak}

Untuk menetapkan besarnya pajakk harus diketahui penghasllan atau laba kena pajak. Undangundang tentang pajak tidak memberikan pedoman yang terperinci untuk menentukan besarnya penghasilan kena pajak, tetapi bukan berarti setiap wajib pajak dapat menghitung pajak menurut kemauannya sendiri. Undang-undang hanya memberikan pedoman yang umum dengan menyatkan bahwa wajib pajak menyelenggarakan pembukuan sehingga dari pembukuan tersebut dapat dihitung penghasilan kena pajak. Kemudian pada akhir tahun pembukuan ditutup dengan membuat neraca dan perhitungan laba rugi berdasarkan prinsip pembukuan. Pembukuan dapat dilakukan sesuai prinsip 
Muhammad Helmi Raditya, Analisis Penerapan Perencanaan Pajak Penghasilan PPh Badan dan Final Sebagai Upaya Mengefisienkan Beban Pajak Pada Perusahaan PT Lippo Karawaci Tbk Tahun 20172019 akuntansi yang berlaku umum di Indonesia, serta menjadi tolak ukur untuk menghitung penghasilan kena pajak.

Perusahaan membuat laporan laba rugi pada akhir tahun untuk melaporkan besarnya laba yang diperoleh, sedangkan dalam melaksanakan kewajiban perpajakannya, perusahaan harus menghitung besarnya pajak yang terutang berdasarkan undang-undang dan peraturan perpajakan karena adanya perbedaan antara akuntansi komersial dan akuntansi pajak, maka perusahaan harus melakukan rekonsiliasi fiskal.

Melalui rekonsiliasi fiskal perusahaan dapat mengetahui biaya dan apa saja yang tidak dapat dikurangi dari penghasilan bruto. Semakin besar yang dilakukan terhadap biaya-biaya maka kemungkinan laba yang dilaporkan perusahaan dalam laporan laba rugi akan lebih kecil dari pada laba fiskal, sehingga perusahaan harus membayar pajak lebih besar. Untuk mengetahui hal tersebut maka dibutuhkan perencanaan pajak (tax planning). Perencanaan pajak merupakan cara yang paling efisien bagi wajib pajak dalam mengambil manfaat secara legal untuk mengurangi atau menghemat pajak penghasilan.

Maka dari itu, penelitian ini membandingkan penerapan sebelum perencanaan pajak dan penerapan sesudah perencanaan pajak (tax planning) melalui laporan laba rugi pada perusahaan. Laporan laba rugi tersebut dianalisis kemudian hasilnya akan dilakukan perbandingan antara laporan laba rugi yang dilakukan perencanaan pajak. Dari analisa dan perbandingan tersebut akan diketahui apakah ada pengaruh atas efisiensi beban pajak yang akan dibayarkan oleh PT Lippo Karawaci Tbk setelah dilakukan perencanaan pajak.

Dalam hal keterkaitannya dengan efisiensi beban pajak, yaitu perusahaan melakukan penerapan perencanaan pajak sesuai dengan perundang-undangan perpajakan yang berlaku dengan cara memaksimalkan biaya fiskal dan meminimalkan biaya yang tidak dapat diperkenankan sebagai pengurang. Dengan begitu perusahaan PT Lippo Karawaci Tbk dapat mengefisiensikan jumlah beban pajak terutangnya sehingga perusahaan dapat membayar pajak dengan hemat.

\section{METODE}

Metode yang digunakan pada penelitian ini adalah metode deskriptif. Penelitian dilakukan di PT. Lippo Karawaci Tbk pada bulan Oktober s.d November tahun 2020 dengan teknik telaah dokumen. Cara menghitung pajak penghasilan adalah dengan mengalihkan tari fpajak dengan penghasilan kena pajak.

Pajak Terutang = Tarif Pajak x Penghasilan Kena Pajak

Perhitungan PPh dengan dasar pembukuan untuk wajib pajak badan.

Penghasilan Kena Pajak = Penghasilan Sebagai Objek Pajak - Biaya 


\section{Formula Perhltungan PPh Badan}

\section{Untuk akhir tahun 200X}

PPh Badan terhutang untuk tahun 200X

A

Dikurangi Kredit pajak :

- $\quad$ PPh Pasal 22

- $\quad$ PPh Pasal 23

$\mathrm{b}$

- PPh Pasal 24

c

- $\quad$ PPh Pasal 25

d

Jumlah kredit pajak B

Pajak penghasilan kurang / lebih bayar / nihil (PPh pasal 29) A - B

\section{Perhitungan PPh Final :}

Rumus PPh Pasal 4 Ayat 2 (UntukPenjual) :

$=$ Tarif $\times$ NJOP atau Akta Jual Beli-NJOPTKP

Rumus BPHTB (Untuk Pembeli) :

$=$ Tarif $\times$ NJOP atau Akta Jual Beli-NJOPTKP

$=$ Tarif $x$ NJOPKP

\section{PEMBAHASAN}

Penerapan pajak yang dilakukan oleh PT. Lippo Karawaci Tbk tidak dapat dipisahkan dengan upaya-upaya yang dilakukan pihak manajemen untuk menyesuaikan dengan peraturan pajak yang berlaku. Perencanaan pajak yang dilakukan pada dasarnya adalah dengan mempertimbangkan aspek perpajakan dan memilih alternatif yang menimbulkan beban pajak yang paling kecil (bila perusahaan dalam kondisi laba).

Tabel 1.

Perbandingan Laporan Laba Rugi

(dalam rupiah)

\begin{tabular}{ccc}
\hline Keterangan & PPh Badan & PPh Final \\
\hline Tahun 2019 & 335.197 .183 & 276.148 .335 \\
Tahun 2018 & 403.247 .684 & 276.424 .450 \\
Tahun 2017 & 228.489 .600 & 276.602 .975 \\
\hline
\end{tabular}

Sumber : PT. Lippo Karawaci Tbk dan diolah oleh penulis

Perhitungan Pajak Penghasilan yang terutang berdasarkan perhitungan Pasal 31E sebagai berikut :

1. Jumlah Penghasilan Kena Pajak (PKP) dari bagian peredaran bruto yang memperoleh fasilitas: 
Muhammad Helmi Raditya, Analisis Penerapan Perencanaan Pajak Penghasilan PPh Badan dan Final Sebagai Upaya Mengefisienkan Beban Pajak Pada Perusahaan PT Lippo Karawaci Tbk Tahun 20172019

$=(\operatorname{Rp} 4.800 .000 .000: \operatorname{Rp} 12.320 .248 .000) \times \operatorname{Rp}(1.665 .165 .000)$

$=\operatorname{Rp}(648.752 .525)$

2. Jumlah Penghasilan Kena Pajak (PKP) dari bagian peredaran bruto yang tidak memperoleh fasilitas :

$\operatorname{Rp}(1.665 .165 .000)-\operatorname{Rp}(648.752 .525) \quad=\operatorname{Rp}(1.016 .412 .475)$

3. Pajak Penghasilan yang terutang :

$25 \% \times 50 \% \times \operatorname{Rp}(648.752 .525)$

$=\operatorname{Rp} \quad(81.094 .065)$

$25 \% \times \operatorname{Rp}(1.016 .412 .475)$

Jumlah Pajak Penghasilan Terutang

$=\underline{\operatorname{Rp}(254.103 .118)+}$

Rp (335.197.183)

Perhitungan Pajak Penghasilan yang terutang berdasarkan perhitungan Pasal 31E sebagai berikut :

1. Jumlah Penghasilan Kena Pajak (PKP) dari bagian peredaran bruto yang memperoleh fasilitas :

$=(\operatorname{Rp} 4.800 .000 .000: \operatorname{Rp} 11.056 .978 .000) \times \operatorname{Rp} 2.060 .165 .000$

$=\operatorname{Rp} 894.348 .528$

2. Jumlah Penghasilan Kena Pajak (PKP) dari bagian peredaran bruto yang tidak memperoleh fasilitas :

Rp 2.060.165.000 - Rp 894.348.528 = Rp 1.165.816.472

Pajak Penghasilan yang terutang :

$25 \%$ x $50 \%$ x Rp 894.348.528

$=\operatorname{Rp} \quad 111.793 .566$

$25 \% \times \operatorname{Rp} 1.165 .816 .472$

Jumlah Pajak Penghasilan Terutang

$=\underline{\operatorname{Rp} \quad 291.454 .118+}$

Rp 403.247.684

Perhitungan Pajak Penghasilan yang terutang berdasarkan perhitungan Pasal 31E sebagai berikut :

1. Jumlah Penghasilan Kena Pajak (PKP) dari bagian peredaran bruto yang memperoleh fasilitas :

$=(\operatorname{Rp} 4.800 .000 .000: \operatorname{Rp} 11.064 .119 .000) \times \operatorname{Rp} 1.167 .129 .000$

$=\operatorname{Rp} 506.341 .191$

2. Jumlah Penghasilan Kena Pajak (PKP) dari bagian peredaran bruto yang tidak memperoleh fasilitas :

$\operatorname{Rp}$ 1.167.129.000 - Rp 506.341.191 = Rp 660.787.809

3. Pajak Penghasilan yang terutang :

$25 \% \times 50 \% \times \operatorname{Rp} 506.341 .191$

$=\operatorname{Rp} \quad 63.292 .648$

$25 \%$ x Rp 660.787 .809

Jumlah Pajak Penghasilan Terutang

$$
=\underline{\operatorname{Rp} \quad 165.196 .952+}
$$

Rp 228.489.600

Hasil dari perhitungan pajak terutang perusahaan PT. Lippo Karawaci Tbk menggunakan PPh Final adalah Rp 276.148.335. Hasil dari perhitungan pajak terutang perusahaan PT. Lippo Karawaci Tbk menggunakan PPh Final adalah Rp 276.424.450. Sedangkan hasil dari perhitungan pajak terutang perusahaan PT. Karawaci Tbk menggunakan PPh Final adalah Rp 276.602.975. 
Muhammad Helmi Raditya, Analisis Penerapan Perencanaan Pajak Penghasilan PPh Badan dan Final Sebagai Upaya Mengefisienkan Beban Pajak Pada Perusahaan

PT Lippo Karawaci Tbk Tahun 20172019

\section{KESIMPULAN}

Berdasarkan pembahasan dan hasil penelitian dapat disimpulkan hal-hal sebagai berikut :

1. Perencanaan pajak dengan menggunakan PPh Badan yang dilakukan PT Lippo Karawaci Tbk sudah sesuai dengan Undang-undang perpajakan yang berlaku, terbukti dari hasil perhitungan laporan laba rugi per tahun PT Lippo Karawaci Tbk. Dari hasil perhitungan setiap tahun, pada tahun 2019 dengan pendapatan sebesar Rp 12.320.248.000 terdapat pajak terutang setelah perencanaan pajak PPh Badan sebesar Rp 335.197.183, pada tahun 2018 dengan pendapatan sebesar Rp 11.056.978.000 terdapat pajak terutang setelah perencanaan pajak PPh Badan sebesar Rp 403.247.684, dan pada tahun 2017 dengan pendapatan sebesar Rp 11.064.119.000 terdapat pajak terutang setelah perencanaan pajak PPh Badan sebesar Rp 228.489.600.

2. Perencanaan pajak dengan menggunakan PPh Final yang dilakukan PT Lippo Karawaci Tbk sudah sesuai dengan Undang-undang perpajakan yang berlaku, terbukti dari hasil perhitungan laporan laba rugi per tahun PT Lippo Karawaci Tbk. Dari hasil perhitungan setiap tahun, pada tahun 2019 dengan pendapatan sebesar Rp 12.320.248.000 terdapat pajak terutang setelah perencanaan pajak PPh Final sebesar Rp 276.148.335, pada tahun 2018 dengan pendapatan sebesar Rp 11.056.978.000 terdapat pajak terutang setelah perencanaan pajak PPh Final sebesar Rp 276.424.450, dan pada tahun 2017 dengan pendapatan sebesar Rp 11.064.119.000 terdapat pajak terutang setelah perencanaan pajak PPh Final sebesar Rp 276.602.975.

3. Perbandingan perhitungan pajak PT Lippo Karawaci Tbk terhadap PPh Badan dan PPh Final yang dibayarkan sesudah penerapan perencanaan pajak terlihat untuk tahun $2019 \mathrm{PPh}$ Badan sebesar Rp 335.197.000 sedangkan PPh Final sebesar Rp 276.148.335, untuk tahun 2018 PPh Badan sebesar Rp 403.247.684 sedangkan PPh Final sebesar Rp 276.424.450, dan untuk tahun 2017 PPh Badan sebesar Rp 228.489.600 sedangkan PPh Final sebesar Rp 276.602.975.

\section{Daftar Pustaka}

Enong Muiz. 2012. Buku Ajar Perencanaan Pajak.Buku 2.Jakarta: Uhamka Press

Erly Suandy, 2016 Edisi 6. Perencanaan Pajak.Jakarta: Penerbit Salemba Empat

Pohan, Chairil. A. 2013. Manajemen Perpajakan. Jakarta: PT. Gramedia Pustaka Utama

Resmi, Siti. 2017. Perpajakan Teori dan Kasus (Edisi ke 10 Buku 1). Jakarta: Salemba Empat.

Saputra, Erick Chandra Adi. 2013. Analisis Penerapan Perencanaan Pajak Sebagai Upaya Meminimalkan Beban Pajak Pada PT Abadi Karya Mulia. Universitas Mercu Buana.

Sanjaya, Wina. 2013. Penelitian Pendidikan, Jenis, Metode dan Prosedur. Jakarta: Kencana Prenada Media Group.

Setyosari, H. P. 2016. Metode penelitian pendidikan E pengembangan. Prenada Media.

Zain, Mohammad. 2015. Manajemen Perpajakan. Salemba Empat: Jakarta.

Zulfa,Laili \& Dini Widyawati. 2013. Penerapan Perencanaan Pajak Pada Pt. X Dalam Meminimalisasi Pajak Sesuai Peraturan perpajakan

Sugiyono. 2014. Metode Penelitian Pendidikan Pendekatan Kuantitatif, Kualitatif, dan RED. Bandung: Alfabeta. 
Muhammad Helmi Raditya, Analisis Penerapan Perencanaan Pajak Penghasilan PPh Badan dan Final Sebagai Upaya Mengefisienkan Beban Pajak Pada Perusahaan PT Lippo Karawaci Tbk Tahun 20172019

Supramono \& Damayanti, Theresia Woro, 2015, Perpajakan Indonesia mekanisme dan perhitungan, Yogyakarta: CV ANDI.

Syaiful, Anwar \& Nurwati, 2019. Penerapan Tax Planning atas Withholding Tax System Terhadap Pengahsilan Pajak Vo 4 No 1. Jurnal Akuntansi Barelang

Swarjana, I Ketut. 2015. Metodologi Penelitian Kesehatan, Edisi Revisi. Yogyakarta: Andi Offset.

Thomas Sumarsan, 2013. Perpajakan Indonesia (Vol.3). Jakarta : PT Indeks.

Ilyas, Wirawan B. dan Rudi Suhartono, 2013. Hukum Pajak Material 1: Seri Pajak Penghasilan. Salemba Humanika.

Yessica, Dewi Aryanti, 2013. Penerapan Perencanaan Pajak Untuk Meminimalkan Pembayaran Pajak Penghasilan Pt $x$ Di Semarang. Jurnal Ilmiah Universitas Surabaya.

Yola, Fahmi Ahmad. 2013. Analisis Perencanaan Pajak (Tax Planning) Dalam Upaya Meningkatkan Efisiensi Beban Pajak Penghasilan Badan Pada PT Akasha Wira Internasional Tbk. Universitas Pakuan Bogor.

Yolina, Meilani S., 2012, Dasar-Dasar Akuntansi Perpajakan, Tabora Media, Jakarta.

Zarai, Mohamed Ali. 2012. The Board of Directors and The Corporate Tax Planning : Emprical Evidence from Tunisia. Universitas Tunis Tunisia.

Erick, Darmawan. 2015. Analisis Penerapan Tax Planning Dalam Usaha Mengefisienkan Beban Pajak Pada Badan Usaha Koperasi. Universitas UIN Syarif Hidayatullah Jakarta.

Erly Suandy, 2016 Edisi 6. Perencanaan Pajak.Jakarta: Penerbit Salemba Empat.

GS, Ahmad Daeng. 2018. Tax Planning Implementation on Income Tax, Article 23 as A Legal Effort To Minimize Tax Expense Payable Vol 4 No 1.Jurnal Terapan Manajemen dan Bisnis

Hutomo, YB. Sigit. 2012. Pengaruh Beban Pajak Tangguhan dan Perencanaan Pajak Terhadap Manajemen Laba. Yogyakarta: Jurnal KINERJA vol 16, No.2, Hal 103-115

Laorens Silitonga. 2013. Penerapan Tax Planning atas Pajak Penghasilan Badan pada CV Andi Offset Cabang Manado. Universitas Sam Ratulangi Manado.

Nawawi, Hadari. 2012. Metode Penelitian Bidang Sosial. Yogyakarta: Gajah Mada University Press

Nurdiansyah, Dian Hakip, Eva Theresna Ruchjana \& Moriska Alfarisi. 2020. The Analysis of Tax Planning Implementation on Added Tax (Case Study at PT Toyotomo Indonesia and PT RKN Forge Indonesia) Vol 7 No 1. Jurnal Ekonomi dan Bisnis Jagaditha

Pratiwi, Anggun Nur. 2013. Analisis Implementasi Tax Planning untuk meminimalkan beban pajak pada PT. Sarana Riam. Universitas Mercu Buana. 